\title{
ON AN INITIAL VALUE REISSNER-SAGOCI PROBLEM
}

\author{
G. M. L. GLADWELL \\ Department of Civil Engineering, University of Waterloo, Waterloo, Ontario, Canada \\ and \\ R. D. LOW \\ Department of Engineering Mechanics, University of Michigan, Ann Arbor, Mich. 48104, U.S.A.
}

\begin{abstract}
A rigid circular cylinder is cemented to the otherwise stress-free surface of a homogeneous isotropic elastic half-space. The cylinder is rotated through a small angle and then released from rest. During the subsequent motion the cylinder remains cemented to the half-space and the problem is the determination of its motion. The problem is solved by setting up an integral equation for the Laplace transform of the angular displacement. Numerical values for the solution of this equation for large and small values of the Laplace parameter $s=i \omega$ can be obtained from the known results for the steady-state Reissner-Sagoci problem. For intermediate values of the parameter the equation is solved by means of Chebyshev approximation. The inversion of the Laplace transform is carried out by using a Laguerre polynomial approximation technique.
\end{abstract}

\section{INTRODUCTION}

CONSIDER an isotropic, homogeneous, elastic half-space which occupies the region $z \geqslant 0$ referred to a cylindrical coordinate system $(r, \theta, z)$. A rigid circular cylinder of mass $m$ and radius $a$, which is cemented to the otherwise stress free surface of the half-space, is slowly rotated through an angle $\epsilon$ and then released from rest. It is assumed that during the subsequent motion, the cylinder remains cemented to the half space and the problem to be considered here is the determination of the motion of the cylinder.

\section{FORMULATION}

If it is assumed that the weight, $m g$, of the cylinder is supported by external means, then the problem is one of torsional motion only, and it is known that the displacement vector has the form $\mathbf{u}=[0, v(r, z, t), 0]$. It then follows that the only non-zero stress components are given by

$$
\sigma_{r \theta}=\mu\left(\frac{\partial v}{\partial r}-\frac{v}{r}\right), \sigma_{\theta z}=\mu \frac{\partial v}{\partial z}
$$

where $\mu$ is the shear modulus of the elastic medium. Let $\delta$ and $c=(\mu / \delta)^{1 / 2}$ denote respectively the mass density and the wave speed in the half-space, and let $\theta(t)$ describe the motion of the cylinder. Then the problem can be stated as follows:

$$
\begin{aligned}
\left(\nabla^{2}-\frac{1}{r^{2}}\right) v= & \frac{1}{c^{2}} v_{t t}, \\
v(r, z, 0)= & v^{0}(r, z), \\
v_{t}(r, z, 0)= & 0, \\
v(r, 0, t)= & r \theta(t), 0 \leqslant r \leqslant a, \\
& 447
\end{aligned}
$$




$$
\begin{aligned}
v_{z}(r, 0, t) & =0, a<r<\infty \\
\frac{1}{2} m a^{2} \ddot{\theta}(t) & =2 \pi \mu \int_{0}^{a} r^{2} v_{z}(r, 0, t) \mathrm{d} r, \\
\theta(0) & =\epsilon, \dot{\theta}(0)=0 .
\end{aligned}
$$

The function $v^{0}(r, z)$ in (2.2) is the solution of the following static problem.

$$
\left(\nabla^{2}-\frac{1}{r^{2}}\right) v^{0}=0, \quad \begin{aligned}
& v^{0}(r, 0)=\epsilon r, 0 \leqslant r \leqslant a, \\
& v_{z}^{0}(r, 0)=0, a<r<\infty .
\end{aligned}
$$

From the well known solution of this problem[1], we have

$$
\begin{aligned}
& v^{0}(r, 0)=\frac{2 \epsilon}{\pi}\left(r \sin ^{-1} \frac{a}{r}-a \sqrt{1-\frac{a^{2}}{r^{2}}}\right), a \leqslant r<\infty, \\
& v_{z}^{0}(r, 0)=-\frac{4 \epsilon}{\pi} \frac{r}{\sqrt{a^{2}-r^{2}}}, 0 \leqslant r<a ;
\end{aligned}
$$

these boundary values being needed below. It is convenient at this point to reduce the problem to one with zero initial conditions and, at the same time, introduce dimensionless variables. Hence let $u(r, z, t)=v(r, z, t)-v^{0}(r, z)$ and then define

$$
u(a \rho, a \zeta, a \tau / c)=a \epsilon U(\rho, \zeta, \tau), \theta(a \tau / c)=\epsilon \Theta(\tau) .
$$

In terms of $U$ and $\Theta$, we now have

$$
\begin{aligned}
\left(\nabla^{2}-\frac{1}{\rho^{2}}\right) U & =U_{\tau \tau}, \\
U(\rho, \zeta, 0) & =U_{\tau}(\rho, \zeta, 0)=0, \\
U(\rho, 0, \tau) & =\rho[\Theta(\tau)-1], 0 \leqslant \rho \leqslant 1, \\
U_{\zeta}(\rho, 0, \tau) & =0,1<\rho<\infty, \\
\ddot{\Theta}(\tau) & =\frac{\pi \lambda}{8} \int_{0}^{1} \rho^{2} U_{\zeta}(\rho, 0, \tau) \mathrm{d} \rho-\frac{\lambda}{3}, \\
\Theta(0) & =1, \dot{\Theta}(0)=0,
\end{aligned}
$$

where $\lambda=32 \mu a^{3} / m c^{2}$ is a dimensionless parameter, the physical significance of which becomes evident if we recall that $c^{2}=\mu / \delta$. For then we have

$$
\lambda=32 a^{3} \delta / \pi a^{2} h \delta_{c},
$$

where $h$ and $\delta_{c}$ are respectively the height and mass density of the cylinder. Hence $\lambda$ is proportioned to $\delta / \delta_{c}$. Thus large (small) $\lambda$ means that the mass of the cylinder is 
much less (greater) than the mass of a portion of the half space whose volume is equal to that of the cylinder.

\section{REDUCTION TO A FREDHOLM EQUATION}

Let $\bar{U}(\rho, \zeta, s)$ and $\bar{\Theta}(s)$ denote the Laplace transforms of $U$ and $\Theta$ respectively. Then (2.10) through (2.15) become

$$
\begin{aligned}
{\left[\nabla^{2}-\left(s^{2}+\frac{1}{\rho^{2}}\right)\right] \bar{U} } & =0, \\
\bar{U}(\rho, 0, s) & =\rho\left[\bar{\Theta}(s)-\frac{1}{s}\right], 0 \leqslant \rho \leqslant 1, \\
\bar{U}_{z}(\rho, 0, s) & =0,1<\rho<\infty \\
\bar{\Theta}(s)-\frac{1}{s} & =-\frac{\lambda}{3 s^{3}}+\frac{\pi \lambda}{8 s^{2}} \int_{0}^{1} \rho^{2} \bar{U}_{5}(\rho, 0, s) \mathrm{d} \rho .
\end{aligned}
$$

We take, as a sufficiently general solution of (3.1), the integral representation

$$
\vec{U}(\rho, \zeta, s)=\int_{0}^{\infty} \frac{\alpha A(\alpha, s)}{\sqrt{\alpha^{2}+s^{2}}} J_{1}(\alpha \rho) \mathrm{e}^{-\xi \sqrt{\alpha^{3}+s^{2}}} \mathrm{~d} \alpha,
$$

where $A(\alpha, s)$ is to be determined from (3.2)-(3.4). The factor $\alpha\left(\alpha^{2}+s^{2}\right)^{-1 / 2}$ could, of course, have been included in $A(\alpha, s)$, but the above form has some convenience. If we impose (3.2) and (3.3), we find

$$
\begin{aligned}
& \int_{0}^{\infty} \frac{\alpha A(\alpha, s)}{\sqrt{\alpha^{2}+s^{2}}} J_{1}(\alpha \rho) \mathrm{d} \alpha=\rho\left[\bar{\Theta}(s)-\frac{1}{s}\right], 0 \leqslant \rho \leqslant 1, \\
& \int_{0}^{\infty} \alpha A(\alpha, s) J_{1}(\alpha \rho) \mathrm{d} \alpha=0,1<\rho<\infty .
\end{aligned}
$$

Condition (3.7) is satisfied identically if, following Noble [2], for instance, we take

and if we write

$$
A(\alpha, s)=\int_{0}^{1} \phi(\xi, s) \sin \alpha \xi \mathrm{d} \xi
$$

$$
\frac{\alpha}{\sqrt{\alpha^{2}+s^{2}}}=1-\left(1-\frac{\alpha}{\sqrt{\alpha^{2}+s^{2}}}\right)=1-g(\alpha, s), \text { say, }
$$

then (3.6) can be reduced to the Abel type equation

$$
\int_{0}^{\rho} \frac{x}{\sqrt{\rho^{2}-x^{2}}}\left[\phi(x, s)+\int_{b}^{1} K(x, \xi, s) \phi(\xi, s) \mathrm{d} \xi\right] \mathrm{d} x=\rho^{2}\left[\bar{\Theta}(s)-\frac{1}{s}\right], \quad 0 \leqslant \rho \leqslant 1,
$$

in which

$$
K(x, \xi, s)=-\frac{2}{\pi} \int_{0}^{\infty} g(\alpha, s) \sin \alpha x \sin \alpha \xi \mathrm{d} \alpha
$$


The 'solution' of (3.9) gives

$$
\phi(x, s)+\int_{0}^{1} K(x, \xi, x) \phi(\xi, s) \mathrm{d} \epsilon=\frac{4 x}{\pi}\left[\bar{\Theta}(s)-\frac{1}{s}\right], \quad 0 \leqslant x \leqslant 1 .
$$

$\dagger$ At this point, we introduce a function $\psi(x, s)$ related to $\phi(x, s)$ and $\widetilde{\Theta}(s)$ by

$$
\psi(x, s)=\frac{\pi}{4} \frac{\phi(x, s)}{\bar{\Theta}(s)-(1 / s)},
$$

and then $(3.10)$ becomes

$$
\psi(x, s)+\int_{0}^{1} K(x, \xi, s) \psi(\xi, s) \mathrm{d} \xi=x, 0 \leqslant x \leqslant 1 .
$$

This is the desired Fredholm equation which will be treated in a later section.

4. MOTION OF THE CYLINDER AND BOUNDARY VALUES IN TERMS OF $\psi$

There are four quantities of physical interest in this problem; namely: the torsional displacement of the cylinder, the related torque acting on the cylinder, and the boundary values of the stress and displacement distributions in the half space. From (3.5) and (3.8) it is a simple matter to show that

$$
\int_{0}^{1} \rho^{2} \bar{U}_{\zeta}(\rho, 0, s) \mathrm{d} \rho=-2 \int_{0}^{1} x \phi(x, s) \mathrm{d} x,
$$

and then from (3.4) and (3.11) we find that

$$
\bar{\Theta}(s)-\frac{1}{s}=-\frac{\lambda / 3 s^{3}}{1+\lambda \Psi(s) / s^{2}}
$$

where

$$
\Psi(s)=\int_{0}^{1} x \psi(x, s) \mathrm{d} x
$$

Hence we find upon inversion of (4.1)

$$
\Theta(\tau)=1 \quad L^{-1}\left[\frac{\lambda / 3 s^{3}}{1+\lambda \Psi(s) / s^{2}}\right]
$$

where $L^{-1}$ denotes the inverse Laplace transform. Next if $q(t)$ is the torque acting on the cylinder so that

$$
q(t)=-2 \pi \int_{0}^{a} r^{2} \sigma_{\theta z}(r, 0, t) \mathrm{d} r .
$$

then it is a simple matter to obtain

$$
Q(\tau)=L^{-1}\left[\frac{1}{s\left(1+\lambda \Psi(s) / s^{2}\right)}\right]
$$

†For this suggestion, the authors are indebted to Professor K. Stewartson. 
where the dimensionless torque $Q(\tau)$ is related to $q(t)$ by

$$
q(a \tau / c)=\psi \mu \epsilon a^{3} Q(\tau)
$$

Finally we introduce the dimensionless stress and displacement components $\boldsymbol{\Sigma}_{\theta z}(\rho, \zeta, \tau)$ and $V(\rho, \zeta, \tau)$ where

$$
\sigma_{\theta z}(a \rho, a \zeta, a \tau / c)=\mu \epsilon \sum_{\theta z}(\rho, \zeta, \tau), v(a \rho, a \zeta, a \tau / c)=\epsilon a V(\rho, \zeta, \tau),
$$

then one can show that the boundary values of these functions are given by

$$
\sum_{\theta z}(\rho, 0, \tau)=-\frac{4}{\pi}\left[\frac{\rho}{\sqrt{1-\rho^{2}}}-L^{-1}\left\{\left(\bar{\Theta}(s)-\frac{1}{s}\right) \frac{\partial}{\partial \rho} \int_{\rho}^{1} \frac{\psi(x, s) \mathrm{d} x}{\sqrt{x^{2}-\rho^{2}}}\right\}\right], \quad 0 \leqslant \rho \leqslant 1,
$$

and

$$
\begin{aligned}
& V(\rho, 0, \tau)= \frac{2}{\pi}\left[\left(\rho \sin ^{-1} \frac{1}{\rho}-\sqrt{1-\frac{1}{\rho^{2}}}\right) \Theta(\tau)\right. \\
&\left.+\frac{2}{\rho} L^{-1}\left\{\left(\bar{\Theta}(s)-\frac{1}{s}\right) \int_{1}^{\rho} \frac{x \mathrm{~d} x}{\sqrt{\rho^{2}-x^{2}}} \int_{0}^{1} K(x, \xi, s) \psi(\xi, s) \mathrm{d} \xi\right\}\right], \\
& 1 \leqslant \rho \leqslant \infty
\end{aligned}
$$

To perform the inversions indicated in (4.3) through (4.6), one obviously needs $\psi(x, s)$ and the related function $\Psi(s)$. Since it does not seem possible to obtain even the first of these functions in closed form, we present, in the next two sections, a numerical procedure. The numerical problem may be divided into two parts. First the solution of the integral equation (3.12) for $\psi(x, s)$ which, together with $\Psi(s)$, permits the formation of the transforms in (4.3)-(4.6); and second the (numerical) inversion of these transforms. It was found that an unwarrantable amount of computing would be required in the second step in so far as (4.5) and (4.6) are concerned. Therefore, attention was directed to the problem of computing $\Theta(\tau)$ and $Q(\tau)$ in (4.3) and (4.4). It is convenient to consider the second step first.

\section{NUMERICAL INVERSION OF THE LAPLACE TRANSFORMS}

If it is assumed that the integral equation for $\psi(x, s)$ has been solved so that $\bar{\Theta}(s)$ and $\bar{Q}(s)$ are known, then the inverse transforms $\Theta(\tau)$ and $Q(\tau)$ may be found by using the numerical procedure described by Weeks[3]. In this method, it is supposed that an inverse transform $f(\tau)$, say, can be approximated by a Laguerre expansion of the form

$$
f_{N}(\tau)=\mathrm{e}^{\gamma \tau} \sum_{n=0}^{N} a_{n} \Phi_{n}(\tau / T)
$$

where $T$ is a scale factor, $\gamma$ is somewhat greater than the abscissa of convergence of the transform $g(s)$ of $f(\tau)$, and the dash indicates that only one half of the first term is 
to be taken. The function $\Phi_{n}(x)$ is the orthonormal Laguerre function $\mathrm{e}^{-x / 2} L_{n}(x)$. The transform of $f_{N}(\tau)$ is

$$
g_{N}(s)=\sum_{n=0}^{N} a_{n} \frac{(s-\gamma-1 / 2 T)^{n}}{(s-\gamma+1 / 2 T)^{n+1}}
$$

and it can be shown that on the line $\operatorname{Re}(s)=\gamma$, in the complex $s$-plane, the function $g_{N}(\gamma+i \omega)$ converges in the mean to $g(\gamma+i \omega)$. The coefficients $a_{n}$ may be found approximately by evaluating $g(\gamma+i \omega)$ at the $N+1$ points $\gamma+i \omega_{k}$, where

$$
\omega_{k}=\frac{1}{2 T} \cot \left(\theta_{k} / 2\right), \theta_{k}=\frac{2 k+1}{N+1} \frac{\pi}{2}, k=0,1, \ldots, N .
$$

It is found that if

$$
g(\gamma+i \omega)=g_{1}(\gamma, \omega)+i g_{2}(\gamma, \omega)
$$

then

$$
a_{n}=\frac{2}{N+1} \sum_{k=0}^{N} h\left(\theta_{k}\right) \cos n \theta_{k}
$$

where

$$
h\left(\theta_{k}\right)=\frac{1}{2 T} g_{1}\left(\gamma, \omega_{k}\right)-\omega_{k} g_{2}\left(\gamma, \omega_{k}\right)
$$

In the problem under consideration $\gamma$ was taken to be zero since the displacement and torque are exponentially decaying functions of $\tau$. In accordance with the suggestion of Weeks, the scale factor $T$ was chosen to be $\tau_{\max } / N$, where $\tau_{\max }$ is the greatest value of $\tau$ for which $\Theta(\tau)$ and $Q(\tau)$ are required. Before this method can be applied it is necessary to find the values of $\Psi(s)$ for the sequence of points $s_{k}=i \omega_{k}$. These values will now be found.

\section{NUMERICAL SOLUTION OF (3.12)}

For purely imaginary values of $s$, the quantity $\Psi(s)$ is proportional to the torque $Q_{s t}$ applied to the half-space in the steady torsional vibration problem. In fact, $\Psi(i \omega)=$ $Q_{s t} / 16 \mu \epsilon a^{3}$. For small values of the (dimensionless) frequency $\omega, Q_{s t}$ may be expanded as a power series in $\omega$. Collins [4] shows that

$$
\Psi(i \omega)=\frac{1}{3}\left(1-\frac{\omega^{2}}{5}+\frac{4 i \omega^{3}}{9 \pi}+\frac{11 \omega^{4}}{105}-\frac{56 i \omega^{5}}{225 \pi}+\cdots\right)
$$

Thomas [5] has given an expansion for $Q_{s t}$ which is valid for large values of $\omega$; that is, for $\omega \geqslant 3$. This gives

$$
\Psi(i \omega)=\frac{i \omega \pi}{16}\left[\frac{1}{2}-\frac{i}{\omega}-\frac{3}{4 \omega^{2}}-\frac{\mathrm{e}^{-2 i \omega+i \pi / 4}}{4\left(\pi \omega^{5}\right)^{1 / 2}}-\frac{3 i}{8 \omega^{3}}+\frac{233 i \mathrm{e}^{-2 i \omega+i \pi / 4}}{256\left(\pi \omega^{7}\right)^{1 / 2}}+O\left(\omega^{-4}\right)\right]
$$

It remains to find $\Psi(i \omega)$ for intermediate values of $\omega$; that is, for $\omega$ in the range $[1,3]$. To do this, equation (3.12) was solved numerically by using the Chebychev expansion 
technique described by Elliott and Warne[6]. In this method the range of the integration, $(0,1)$ in the present case, is first transformed to $(-1,1)$ by means of the transformations

$$
y=2 x-1, \eta=2 \xi-1, \psi(x, s)=\psi^{*}(y, s)
$$

and the function $\psi^{*}(y, s)$ is approximated by a Chebychev series

$$
\psi^{*}(y, s)=\sum_{k=1}^{M+1} e_{k}(s) T_{k-1}(y)
$$

The kernel $K(x, \xi, s)=K^{*}(y, \eta, s)$ is expanded in a similar way, and the integration

$$
\int_{-1}^{1} K^{*}(y, \eta, s) \psi^{*}(\eta, s) \mathrm{d} \eta
$$

is carried out exactly. The left and right hand sides of the equation are equated for the $M+1$ Chebychev points $\cos [\pi(k-1) / M], k=1,2, \ldots, M+1$, and the resulting equations are solved to find the coefficients $e_{k}(s)$. In the present problem the kernel $K(x, \xi, s)$ is given by

$$
K(x, \xi, s)=-\frac{2}{\pi} \int_{0}^{\infty}\left(1-\frac{\alpha}{\sqrt{\alpha^{2}+s^{2}}}\right) \sin \alpha x \sin \alpha \xi \mathrm{d} \alpha .
$$

Complex integration around the contour consisting of the real axis with indentations in the upper half plane at $\pm \omega$ shows that

$$
K(x, \xi, i \omega)=G(x+\xi)-G(|x-\xi|),
$$

where

$$
G(u)=\frac{i \omega}{\pi}+\frac{\omega}{2}\left[J_{1}(\omega u)-i H_{1}(\omega u)\right]
$$

and $J_{1}$ and $H_{1}$ are respectively the Bessel and Struve functions of the first kind. Since $K$ is complex, so is $\psi$ and the whole computation has to be carried out in complex arithmetic. In addition, since $\partial K^{*} / \partial y$ has a discontinuity at $y=\eta$, the range of integration $(-1,1)$ has to be divided into $(-1, \eta)$ and $(\eta, 1)$, as described in [6]. Once the coefficients $e_{k}(s)$ have been found, the quantity $\Psi(s)$ may be computed from

where

$$
\Psi(s)=\int_{0}^{1} \xi \psi(\xi, s) \mathrm{d} \xi=\frac{1}{4} \int_{-1}^{1}(\eta+1) \psi^{*}(\eta, s) \mathrm{d} \eta=\sum_{k=1}^{M+1} b_{k} e_{k}(s),
$$

$$
b_{k}=\left\{\begin{array}{l}
-2[(k+1)(k-3)]^{-1}, k \text { even } \\
-2[k(k-2)]^{-1}, k \text { odd }
\end{array}\right.
$$

7. NUMERICAL RESULTS

The numerical procedure runs as follows: First the number of terms to be taken in the Laguerre expansions (5.1) for $\Theta(\tau)$ and $Q(\tau)$ is chosen. Then the values of $\Psi(s)$ 
at the $N+1$ points $\omega_{k}$ are calculated. These are fed into equations (5.3)-(5.5) and the functions $\bar{\Theta}(s)$ and $Q(s)$ are inserted to give $\Theta(\tau)$ and $Q(\tau)$, which are then evaluated for a convenient set of $\tau$-values. The following values were chosen: $N=60 . \tau_{\max }=16$. It was found that for values of $\lambda$ less than 4 , more terms were needed in the Laguerre expansion (5.1). This was evident from the fact that the calculated $\Theta(0)$ was not equal to unity, as it should have been. For $N=60, \lambda=2, \Theta(0)=0 \cdot 8$. Four values of $\lambda$ were chosen, namely $4,8,16$ and 32 . The number of terms needed in the Chebychev expansions of $\psi^{*}(y, s)$ and in the product $K^{*}(y, \eta, s) \psi^{*}(\eta, s), M+1$ and $P+1$ respectively, were found to increase with $\omega$. It was found that the following values were sufficient:

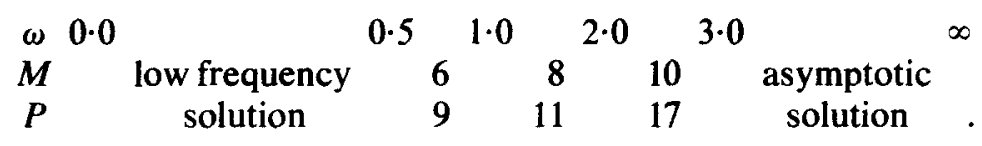

Figure 1 shows how the computed values of $\Psi(i \omega)$, obtained for intermediate values of $\omega$, bridge the gap between the low frequency solution (6.1) and the asymptotic solution (6.2). Notice that the scale for the imaginary part of $\Psi(i \omega)$ is ten times that for the real part. Figures 2 and 3 show the computed values of $\Theta(\tau)$ and $Q(\tau)$ for the four chosen values of $\lambda$.

\section{CONCLUSIONS}

Almost all of the Fredholm integral equations arising from elastic contact problems have, until recently, been solved using either analytical or iterative techniques. Examples of analytical work are provided by Sneddon[1] etc., papers using some form of the method described by Noble[2], and others using the Wiener-Hopf technique, for example Spence $[7,8]$. Iterative methods have been applied to problems in which the

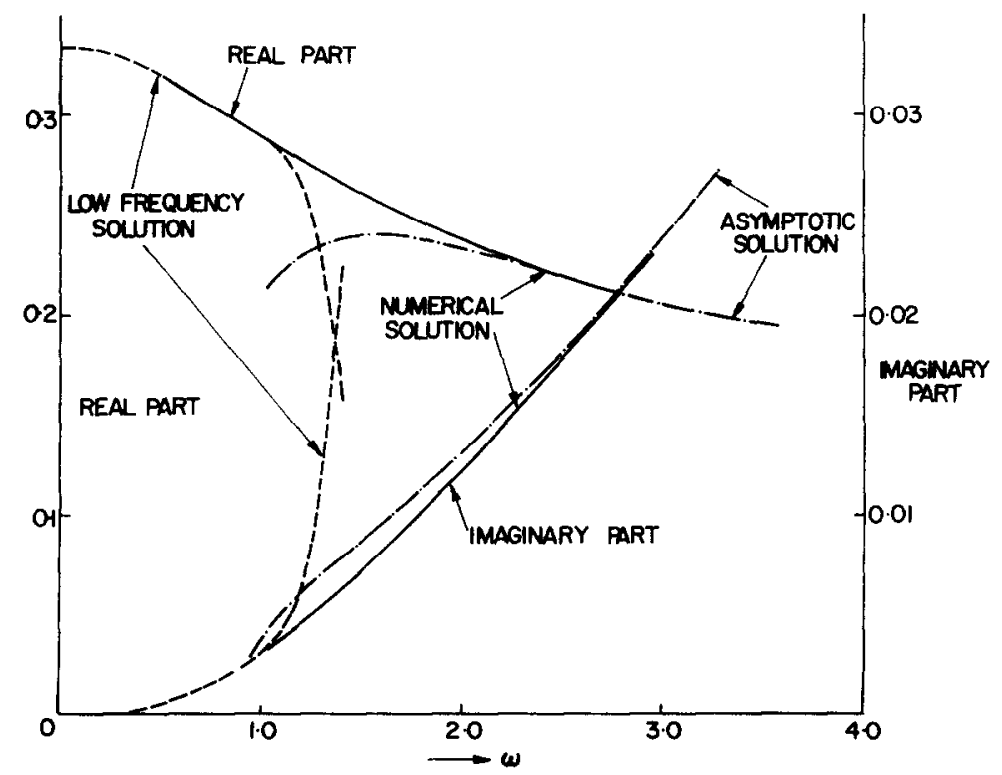

Fig. 1. 


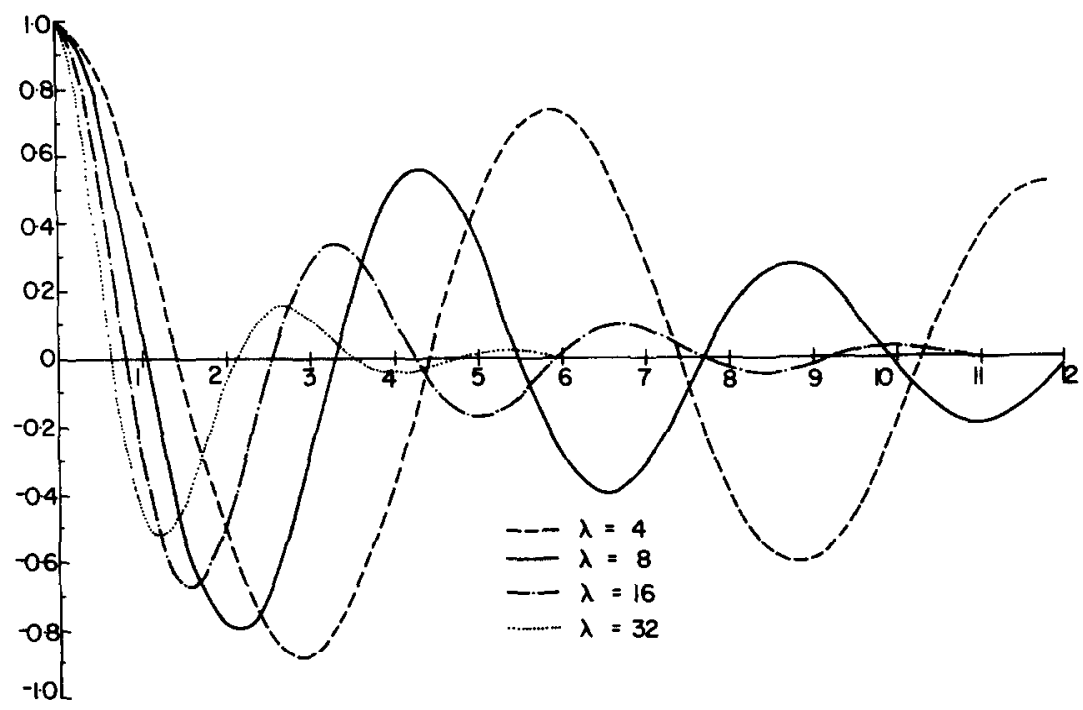

Fig. 2.

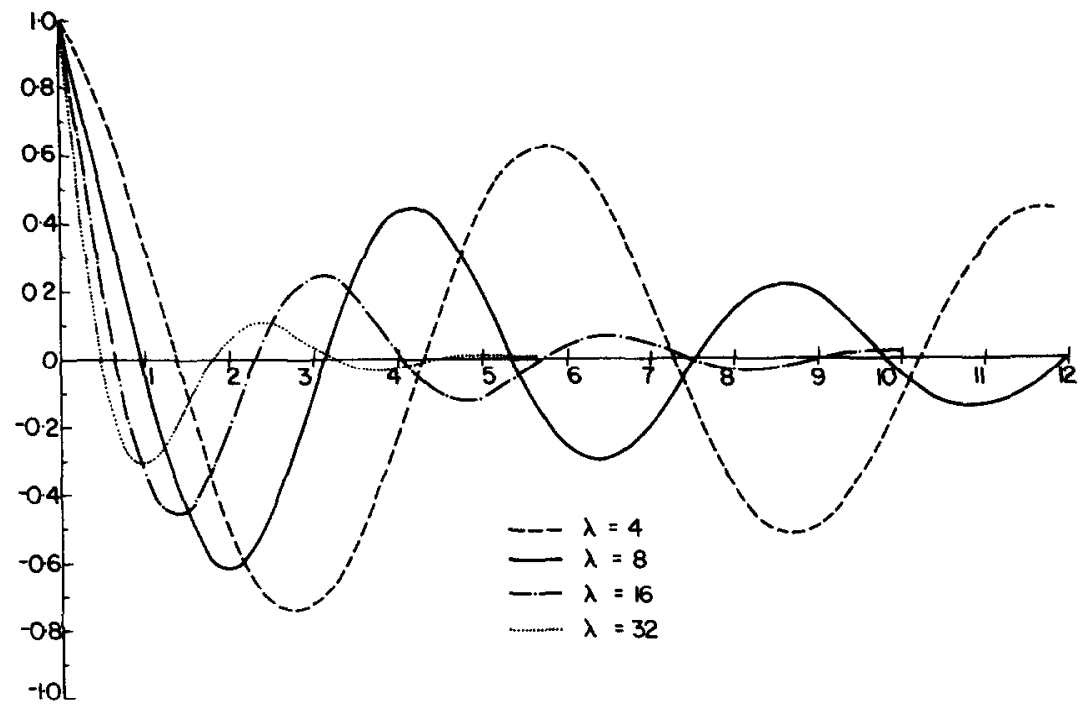

Fig. 3.

kernel contains a small parameter, for instance, in dynamic contact problems in which the reduced frequency is small, e.g., Robertson [9]. Recent examples of direct numerical solution are provided by the work of Noble and Hussain[10] in which the integral equation is solved using variational techniques, and Karasudhi, Keer and Lee[11], in which the integral is approximated by using the trapezoidal rule. The present paper shows that the Chebychev method of [6] which is simple to program, and gives high accuracy for a small number of terms, may be used as a useful adjunct to analytical methods. 


\section{REFERENCES}

[1] I. N. SNEDDON, J. appl. Phys. 18, 130 (1947).

[2] B. NOBLE, Proc. Camb. phil. Soc. 59. 351 (1963).

[3] W. T. WEEKS, J. Ass. comput. Mach. 13, 419 (1966).

[4] W. D. COLLINS, Proc. Lond. math. Soc. Series 3,12, 226 (1962).

[5] D. P. THOMAS, Q.JlMech. appl.Math. 21, 51 (1968).

[6] D. E. ELLIOT and W. G. WARNE. ICC Bull. 6, 207 (1967).

[7] D. A. SPENCE, Proc. R. Soc. A305, 55 (1968).

[8] D. A. SPENCE, Proc. R. Soc. A305, 81 (1968).

[9] I. A. ROBERTSON, Appl. scient. Res. 17, 305 (1967).

[10] B. NOBLE and M. HUSSAIN, J. Inst. Math. Applics 5, 194 (1969).

[11] P. KARASUDHI, L. M. KEER and S. L. LEE, J. appl. Mech. Series E. 35. 697 (1968).

(Received 15 October 1969)

Résumé - Un cylindre circulaire rigide est cimenté sur une surface d'un semi-espace isotrope homogène élastique. qui ne subit aucune autre tension. Le cylindre est tourné de quelques degrés et ensuite libéré de sa position de repos. Durant le mouvement subséquent. le cylindre reste cimenté au semi-espace et le problème consiste à en déterminer le mouvement. Ce problème est résolu par l'établissement d'une intégrale ayant trait à la formule de transformation de Laplace du déplacement angulaire. On peut obtenir des valeurs chiffrées pour la solution de cette équation. aussi bien pour les grandes que les petites valeurs du paramètre de Laplace $s=i \omega$. en se basant sur les résultats connus du problème Reissner-Sagoci de l'état stable. En ce qui concerne les valeurs intermédiaires de ce paramètre, la méthode d'approximation de Chebyshev permet de résoudre cette équation. L'inversion de la formule de transformation de Laplace est réalisée en recourant à la technique d'approximation par polynôme de Laguerre.

Zusammenfassung - Ein starrer kreisformiger Zylinder ist an die sonst spannungsfreie Oberfläche eines homogenen isotropischen elastischen Halbraumes zementiert. Der Zylinder wird durch einen kleinen Winkel rotiert und dann aus dem Ruhezustand freigelassen. Während der darauf folgenden Bewegung bleibt der Zylinder an den Halbraum befestigt und das Problem ist das der Bestimmung seiner Bewegung. Das Problem wird durch das Aufstellen einer Integralgleichung fiir das Laplace-Transform der Winkelverschiebung gelöst. 7ahlenwerte für die Lösung dieser Gleichung fïr hohe und niedrige Werte des Laplace-Parameters $s=i \omega$ können von den bekannten Resultaten für das Stabilzustands-Reissner-Sagoci-Problem erhalten werden. Für Zwischenwerte des Parameters wird die Gleichung mit Hilfe von Chebyshev-Annäherung gelöst. Die Umkehrung des Laplace-Transforms wird unter Beniitzung einer Laguerre'schen polynomischen Annäherungsmethode durchgefuihrt.

Sommario - Si cementa un cilindro circolare rigido a una superficie libera da sollecitazioni di un semispazioni di un semispazio elastico isotropico omogeneo. Si fa ruotare il cilindro su un piccolo angolo e lo si rilascia dalla posizioni di riposo. Durante il successivo movimento il cilindro permane cementato al semispazio e il problema consiste nel determinarne il movimento. Il problema é risolto impostando un'equazione integrale per la trasformazione di Laplace dello spostamento angolare. In base ai risultati noti del problama di stato immobile di Reissner-Sagoci si possono ricavare valori numerici per la soluzione di quest'equazione per valori grandi e piccoli del parametro di Laplace $s=i \omega$. Per $i$ valori intermedi del parametro si risolve l'equazione mediante l'approssimazione di Chebyshev. L'inversione della trasformazione di Laplace è effettuata impiegando il metodo d'approssimazione polinomiale di Laguerre.

\footnotetext{
Абстракт-Цементирован жесткий кругловый цилиндр к поверхности однородного изотропинеского эдастичного полупространства, иначе ненапряженной. Цилиндр вращается через малый угол и освобождается от состоянии нокоя. В последуюшим движением цилиндр еше цементирован $к$ полупространству, задача состоит в том, что нужно определить его движение. Для решения этой проблемы, получено интегральное уравнение для изображения функции по Лапласу углового сжещения. Численные значения для полученного решения этого уравнения можно получить для малых и больших значений параметра Лапласа $s=i \omega$, исполззуя известные результаты для стационарной задачи Рейсснер-Саяосиевской. Исползована аппроксимация Чебышева для решения уравения при промежуточных значениях параметра. Оригинал преобразования Лапласа осуществляется при помоци метола аппроксимации многочпена Лаяерра.
} 